SHORT REPORT

\title{
The Livingston Paediatric Dose Calculator
}

\author{
Matthew J Reed, Jane Fothergill
}

Emerg Med J 2007;24:567-568. doi: 10.1136/emj.2007.046698

The Livingston Paediatric Dose Calculator is presented and its use explained. It may be of benefit in emergency departments that do not regularly see large numbers of children requiring drug treatment.

$\mathrm{P}$ aediatric dose calculators are not a new concept. Many are available for use in the paediatric intensive care setting, having been designed by anaesthetists and intensivists in order to aid what are often sometimes complicated calculations. ${ }^{1}$ There is some evidence that use of a computerised calculator reduces prescribing error rates, ${ }^{2}$ and may be significantly faster than manual paper based calculation. ${ }^{3}$ The paediatric anaesthesia departments at both The Royal Aberdeen Children's Hospital (http://www.abdn.ac.uk/ ans087/trustwebsite/PICU.xls) and The Royal Hospital for Sick Children, Edinburgh (http://www. snprs.scot.nhs.uk/Paediatric\%20 Drug\%20Dose\%20Calculator. xls) have developed excellent free on-line paediatric drug calculators; there are also numerous commercially available programmes, although many of these are US-based and therefore not useful in a UK setting.

While dose calculators are extremely useful for children requiring resuscitation and intensive care treatment, they may also benefit patients presenting to emergency departments (EDs) requiring treatment for conditions such as asthma or seizures, or requiring analgesia for orthopaedic injuries. A search of the medical literature and of Google revealed only one

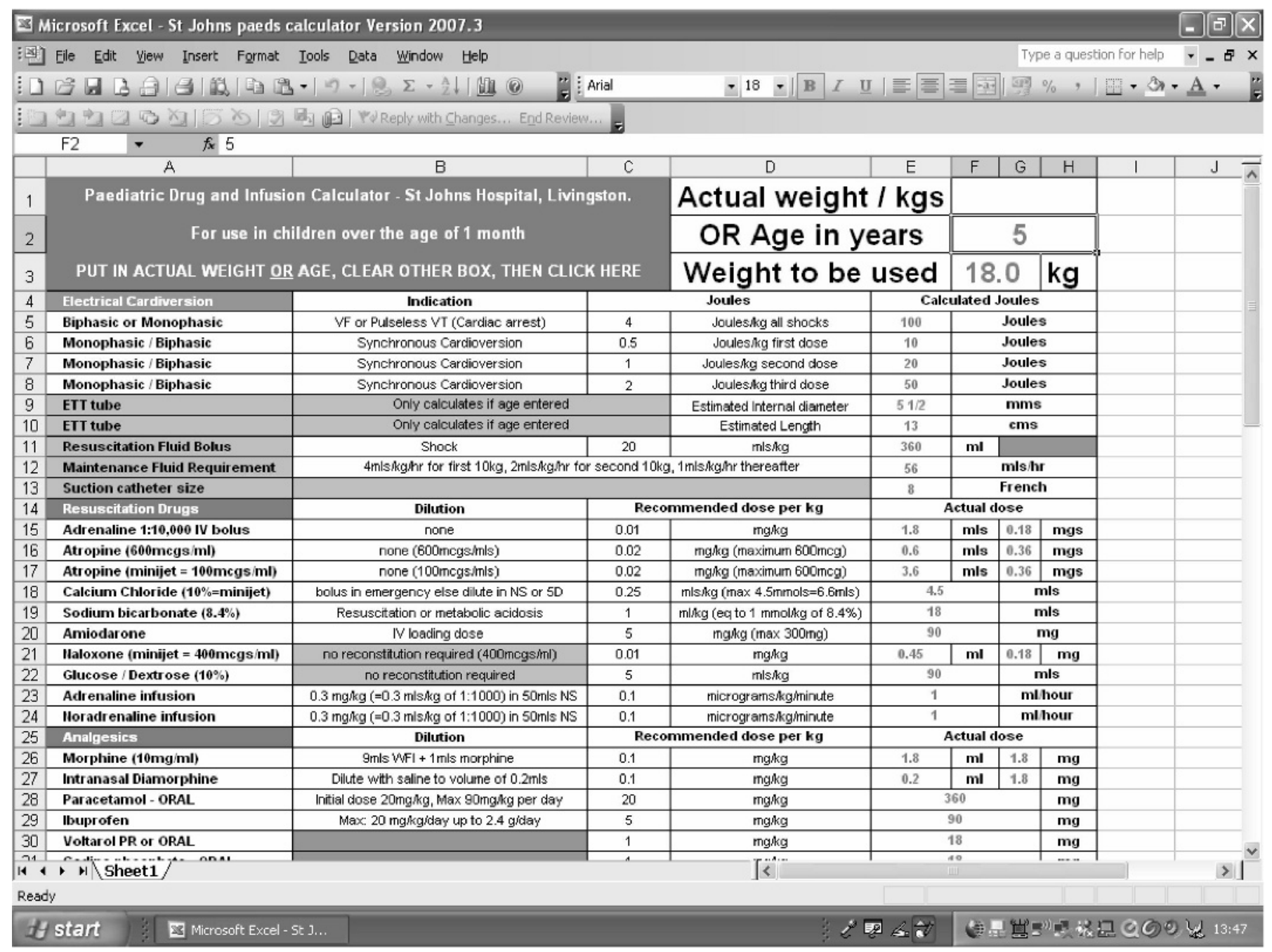

Figure 1 Screenshot from the Livingston Paediatric Dose Calculator. 
calculator specifically designed for use in UK EDs. This was not solely for use in the paediatric population and is not freely available. ${ }^{3}$ It was for this reason that the Livingston Paediatric Dose Calculator was developed.

The calculator, developed as a Microsoft Excel document, is available on a computer in our ED's resuscitation room at St John's Hospital. The programme is accessed either via the desktop or via the ED guidelines on the hospital's intranet site. On opening the file, a screen similar to that shown in fig 1 appears. The user enters either the patient's age or weight if it is known, and then clicks on the large grey box on the left of the screen at which point 72 instant calculations are performed and the results displayed. The calculator is able to aid resuscitation, analgesic, fluid and antibiotic administration, rapid sequence induction, and the treatment of cardiac conditions, seizures, anaphylaxis, asthma and many other paediatric conditions.

If enough warning and information is available from the ambulance service of an imminent admission, then the age of the child can be entered into the calculator and a sheet can be printed out immediately, with all drug doses for reference. Once the child arrives, then either an age or an actual weight can be entered into the calculator to improve accuracy. The calculator can also be used online. As with all such calculators it is vital that the drug dose is double checked by a second person before medication is administered. The calculator is freely available for use via EMJ online at http://emj.bmj.com/supplemental.

\section{ACKNOWLEDGEMENTS}

The original idea for the Livingston Paediatric Dose Calculator was inspired by an Australian version designed by Dr Richard Lennon of the
Royal North Shore Emergency Department in Sydney, New South Wales, Australia.

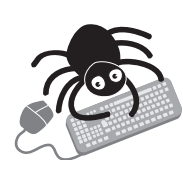

The Livingston Paediatric Dose Calculator is available online at http://emj.bmj.com/supplemental

\section{Authors' affiliations \\ Matthew J Reed, Jane Fothergill, Department of Emergency Medicine, St John's University Hospital, Livingston, West Lothian, UK}

Competing interests: none

Correspondence to: Dr Matthew Reed, Department of Emergency Medicine, Royal Infirmary of Edinburgh, 51 Little France Crescent, Edinburgh, EH16 4SA, UK; mattreed1@hotmail.com

Accepted 10 April 2007

\section{REFERENCES}

1 Vaidya V. CPOE revisited: a computerized calculator for continuous medication infusions. Pediatric Critical Care Med 2006;7:282-3.

2 Lehmann CU, Kim GR, Gujral R, et al. Decreasing errors in pediatric continuous intravenous infusions. Pediatric Critical Care Med 2006;7:225-30.

3 Shannon T, Ratchford A, Southward D, et al. The development of a computerised equipment and drug calculator for use in resuscitation. Emerg Med J 2002;19:215-8. 